\title{
PERFORMANCE EVALUATION OF HIGH-TEMPERATURE SUPERCONDUCTING CURRENT LEADS FOR ELECTRIC UTILITY SMES SYSTEMS*
}

\author{
R. C. Niemann, Y. S. Cha, J. R. Hull \\ Argonne National Laboratory, Argonne, Ilinois 60439 \\ C. M. Rey, K. D. Dixon \\ Babcock \& Wilcox, Lynchburg, Virginia
}

\begin{abstract}
DISCLAIMER
This report was prepared as an account of work sponsored by an agency of the United States Government. Neither the United States Government nor any agency thereof, nor any of their employees, makes any warranty, express or implied, or assumes any legal liability or responsibility for the accuracy, completeness, or usefulness of any information, apparatus, product, or process disclosed, or represents that its use would not infringe privately owned rights. Reference herein to any specific commercial product, process, or service by trade name, trademark, manufacturer, or otherwise does not necessarily constitute or imply its endorsement, recommendation, or favoring by the United States Government or any agency thereof. The views and opinions of authors expressed herein do not necessarily state or reflect those of the United States Government or any agency thereof.
\end{abstract}

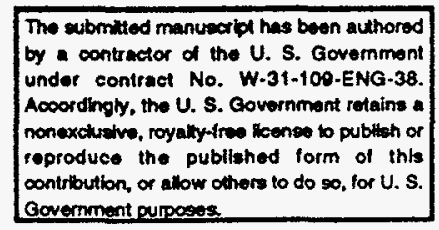

For presentation at 1995 Cryogenic Engineering Conference, July 17-21, 1995, Columbus, $\mathrm{OH}$.

*Work partially supported by the U.S. Department of Energy, Energy Efficiency and Renewable Energy, as part of a program to develop electric power technology, under Contract W-31-109-Eng-38, and by Babcock \& Wilcox, Lynchburg, VA, USA. 


\section{DISCLAIMER}

Portions of this document may be illegible in electronic image products. Images are produced from the best available original document. 


\title{
PERFORMANCE EVALUATION OF HIGH- TEMPERATURE SUPERCONDUCTING CURRENT LEADS FOR ELECTRIC UTILITY SMES SYSTEMS
}

\author{
R. C. Niemann, ${ }^{1}$ Y. S. Cha, ${ }^{1}$ J. R. Hull, ${ }^{1}$ C. M. Rey, ${ }^{2}$ and K. D. Dixon ${ }^{2}$ \\ ${ }^{1}$ Argonne National Laboratory \\ Argonne, IL 60439, USA \\ 2Babcock \& Wilcox \\ Lynchburg, VA 24506, USA
}

\begin{abstract}
As part of the U.S. Department of Energy's Superconductivity Technology Program, Argonne National Laboratory and Babcock \& Wilcox are developing high-temperature superconductor (HTS) current leads for application to electric utility superconducting magnetic energy storage systems. A 16,000-A HTS lead has been designed and is being constructed. An evaluation program for component performance was conducted to confirm performance predictions and/or to qualify the design features for construction. Performance of the current lead assemblies will be evaluated in a test program that includes assembly procedures, tooling, and quality assurance; thermal and electrical performance; and flow and mechanical characteristics. Results of the evaluations to date are presented.
\end{abstract}

\section{INTRODUCTION}

A superconducting magnetic energy storage (SMES) system stores electrical energy to provide power during voltage sags and momentary power losses. SMES devices store electric energy as a circulating current in a magnetic coil.

High-temperature superconductor (HTS) current leads are particularly advantageous for SMES devices because they have the potential to reduce coolant refrigeration requirements to values significantly below the best values achievable with conventional leads.

As part of the U.S. Department of Energy's Superconductivity Technology Program, Argonne National Laboratory is developing, with industry, HTS current leads suitable for application to SMES systems.

\section{MID-SIZED SMES APPLICATION}

Babcock \& Wilcox is engaged in a project to design, build, and demonstrate a mid-sized SMES system, which has been sized in response to the requirements of Anchorage (Alaska) Municipal Light and Power. The 0.5-MWh energy-capacity system, with a discharge power of $30 \mathrm{MW}$, is a basic unit that could be grouped with other modules at a utility site to meet much larger energy storage needs. 


\section{Performance Specifications}

Major elements of the system's performance are given in Table 1.1

\section{General Arrangement}

The general arrangement of the current lead is shown in Fig. 1.

\section{Upper-Stage Current Lead}

Gas-cooled leads (GCLs) are designed to efficiently transmit current from $300 \mathrm{~K}$ to the upper-stage-to-middle-stage transition that operates at $=60 \mathrm{~K}$. Helium gas at $42 \mathrm{~K}$, supplied by a refrigerator, removes the resistive and conductive heat from the GCL itself. The GCL is an adaptation of a vendor-manufactured vapor-cooled lead with a cross section and wetted perimeter based on a standard vapor-cooled design optimized for minimum lower-end heat flow.

\section{Upper-Stage-to-Middle-Stage Transition}

Electrical and structural connection to the upper stage is by a large, fine-pitch screw thread. The mating threaded sections are copper and are plated with nickel and gold to improve electrical and thermal conductance across the joint. The male thread is tinned with indium.

Table 1. Performance requirements of HTS current leads.

\begin{tabular}{ll}
\hline \multicolumn{1}{c}{ Parameter } & \multicolumn{1}{c}{ Design value } \\
\hline $\mathrm{I}_{\mathrm{op}}, \mathrm{V}_{\max }, \mathrm{B}_{\max }$ & $16 \mathrm{kA}, 5 \mathrm{kV}$, SMES + self \\
Dimensions & $0.1 \mathrm{~m}$ diam. $\mathrm{x} \mathrm{m}$ length \\
HTS temperature & $\mathrm{T}_{\text {warm }}<60 \mathrm{~K}, \mathrm{~T}_{\text {cold }}=5 \mathrm{~K}$ \\
Heat leakage @ $5 \mathrm{~K}$ & $<15 \mathrm{~W} / \mathrm{ead}$ \\
$300-60 \mathrm{~K}$ cooling & Helium gas \\
$60-5 \mathrm{~K}$ cooling & Conduction \\
\hline
\end{tabular}

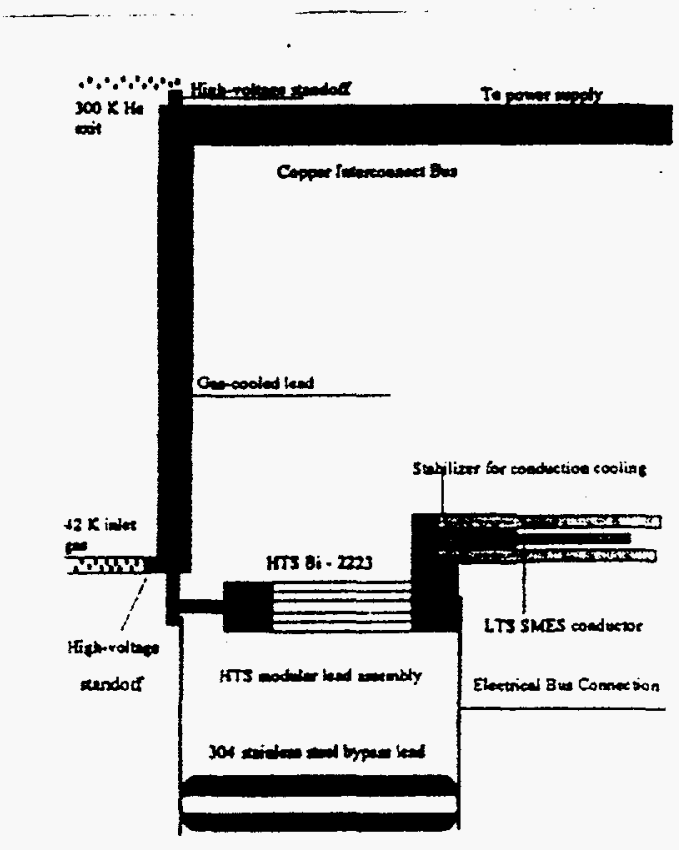

Fig. 1. General arrangement of current lead 
Current flow through the transition can follow two paths. During superconducting operation, all current flows through the female portion of the threaded connection to a circular array of current buses. To accommodate nonuniform contact resistance to the HTS elements, the buses are made of copper and their geometry, area, and length are selected to control the current-sharing among the HTS elements. Bus resistance is designed to be five or more times that of the sum of the other resistances in the current path of the conductor element. During an upset condition corresponding to the HTS elements being in the normal state, a fraction of the current flows through the female portion of the threaded connection to the middle-stage safety lead, while the remaining fraction flows through the conductor element's Ag-Au sheath. The amount of current flowing through the safety lead will depend on the magnitude of the disturbance, which controls the amount of HTS that has become a normal conductor.

Helium gas at $42 \mathrm{~K}$ with a mass flow rate of $2.5 \mathrm{~g} / \mathrm{s}$ is injected at the lower end of the transition. The gas absorbs the ohmic heating of the normal metal components and electrical connections and then enters the upper stage to be cooled.

\section{Middle-Stage Current Lead}

The axial cross section of the middle stage is as shown in Fig. 2. The middle stage incorporates 18 parallel HTS elements configured in a cylindrical array. The conductor elements are supported by an internal safety lead and are connected at their ends to current collectors. Most of the middle stage is cooled by conduction from its 5-K end.

The major features of the selected conductor element are PIT tape with a Bi-2223 multifilamentary core in an $\mathrm{Ag}+3$ at.\% Au sheath, composite conductor of stacked PIT tapes sintered together, critical current of $>1100 \mathrm{~A} @ 60 \mathrm{~K}$ in an applied magnetic field, $4 \mathrm{~K}$ heat load of $\leq 0.4 \mathrm{~W} /$ element, irreversible strain limit of $\geq 0.1 \%$, thermal cycling results in $<4 \%$ predicted degradation in critical current, size $=0.48 \times 1.07 \times 54 \mathrm{~cm}$, and end caps of unalloyed silver.

The safety lead is the core of the middle-stage assembly, which provides an alternate current path and, more importantly, additional thermal mass in the event of HTS element quench. The current path is through a 304 stainless steel tube that is slotted in order to guide and mechanically support the conductor elements. The external surface is nickel- and goldplated. The conductor elements are fixed axially at their warm ends, strain-relieved at their cold ends, and soldered into the slots of the stainless steel cylinder.

The safety lead is designed to limit the temperature of the HTS to $<400 \mathrm{~K}$ during a quench and has a conductive heat leak $<2 \mathrm{~W}$ to $5 \mathrm{~K}$. In the event of catastrophic failure of

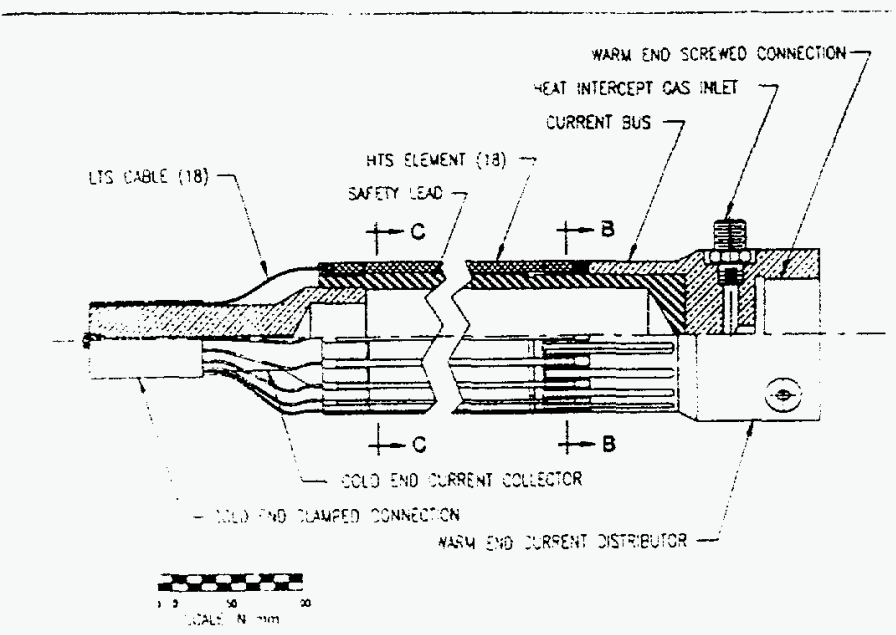

Fig. 2. Axial cross section of middle-stage current lead 
the HTS leads, the burnout time of the safety lead is $>100$ s so that current in the SMES magnet can be brought down to safe levels without causing damage to the magnet and its subsystems.

\section{Middle-Stage-to-Lower-Stage Transition}

The electrical connection to the lower-stage current junction consists of seven twisted parallel low-temperature superconductor (LTS) strands for each conductor element. The strands are shaped to provide axial strain relief. The $5-\mathrm{K}$ heat load due to connection ohmic heating is $1 \mathrm{~W}$.

\section{Lower Stage}

Electrical and structural connection to the middle/lower-stage transition is by a clamp connection. The cross-sectional area and length of the lower-stage copper bus are selected to provide adequate thermal conduction so as to limit the temperature rise of the middle/lowerstage transition to $<1 \mathrm{~K}$. Associated overall ohmic heating is $1.23 \mathrm{~W}$.

\section{Thermal Performance}

Numerical analysis of the HTS lead with a $60-\mathrm{K}$ intercept shows a reduction in a 5-K equivalent heat load by nearly $50 \%$ that of a conventional vapor-cooled lead. This reduction translates to $<100 \mathrm{~W}$ equivalent heat load at $5 \mathrm{~K}$.

\section{EVALUATIONS OF COMPONENT PERFORMANCE}

\section{Upper-Stage-to-Middle Stage Transition}

A threaded connection identical to that of the upper-stage-to-middle-stage transition was constructed and employed to measure the electrical resistance of the joint. The joint resistance vs. ambient assembly torque was measured in $\mathrm{LN}_{2}$. The measured joint resistance was $0.0023 \mu \Omega$, as compared to the predicted value of $0.0015 \mu \Omega$. The resistance is flat with respect to assembly torque for torques greater than $400 \mathrm{~N} \cdot \mathrm{m}(\approx 300 \mathrm{ft}-\mathrm{lb})$.

\section{HTS Conductor Elements}

The conductor elements were constructed from sintered stacks of multifilamentary composite conductor; geometry is as shown in Fig. 3. The conductor is made by the PIT method, and is in the form of an aspected tape 5 composed of fine BSCCO-2223 filaments in a silver/gold alloy matrix.

A test matrix was developed to evaluate the performance of the preproduction conductor elements relative to their performance specifications. The test matrix is given in Table 2.

The current used to evaluate the critical current $\left(I_{c}\right)$ of the preproduction conductor elements was pulsed at a low duty cycle to avoid errors caused by effects of current-contact heating. The $\mathrm{I}_{\mathfrak{c}}$ measurements were made in a facility consisting of a variable-temperature helium cryostat, a superconducting magnet, and a current pulser. The variable-temperature cryostat was configured to contain two samples and was rotatable in the magnet to provide $\mathrm{B} / / \mathrm{b}$ and $\mathrm{B} / \mathrm{c}$ applied field orientations.

Results of the $60 \mathrm{~K} \mathrm{I}_{\mathrm{C}}$ tests of Sample L94-345 in transversely applied magnetic fields are shown in Figs. 4 and 5. As expected, the superconductive performance of both bars was most sensitive to magnetic fields applied in the B//c direction.

A thermal cycling test was performed on Sample L94-345 after the testing in magnetic fields had been completed. Critical current in a $45-\mathrm{cm}-1$ long segment of the bar at $77 \mathrm{~K}$ was measured by the pulsed current technique. Fifty thermal cycles were applied. No significant changes attributable to thermal cycling were found.

An electrical cycling test was performed on Sample L94-346 at $77 \mathrm{~K}$ after the testing in magnetic fields had been completed. The initial $I_{c}$ was found to be $990 \mathrm{~A}$. A total of 600 square-wave current pulses, each of $1000-\mathrm{A}$ amplitude and $>300 \mathrm{~ms}$ length, was then

applied at a low duty cycle. Afterward the $I_{c}$ was found to be $978 \mathrm{~A}$. The values before and after electrical cycling differed by only $0.6 \%$ from their averages. 


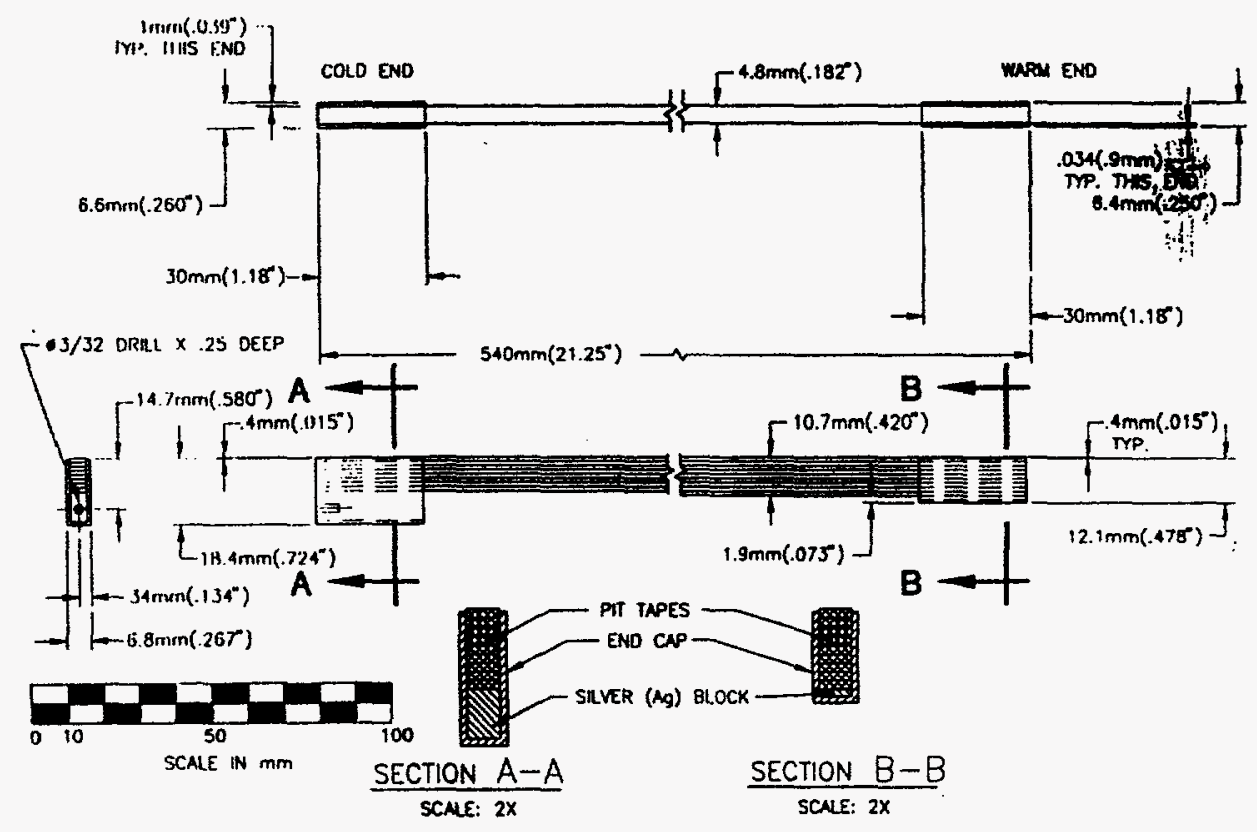

Fig. 3. HTS conductor element geometry

Table 2. Performance evaluation matrix for preproduction conductor element

\begin{tabular}{|c|c|c|}
\hline & Sequence of events, performance evaluation ${ }^{a}$ & Sample \\
\hline 1 & $\begin{array}{l}\mathrm{I}_{\mathrm{c}} @ 77 \mathrm{~K} @ 1 \mu \mathrm{V} / \mathrm{cm} \\
: \quad \mathrm{B}=0 \mathrm{~T} \\
: \quad \mathrm{B}=0.2 \mathrm{~T} \| \mathrm{a} \\
: \quad \mathrm{B}=0.1 \mathrm{~T} \| \mathrm{b} \\
\cdot \quad \mathrm{B}=0.02 \mathrm{~T} \| \mathrm{c}\end{array}$ & $\begin{array}{c}\text { L94-345 \& } \\
\text { L94-346 }\end{array}$ \\
\hline 2 & $\begin{array}{l}\mathrm{I}_{\mathrm{c}} @ 60 \mathrm{~K} @ 1 \mu \mathrm{V} / \mathrm{cm} \quad \text { (in variable-temperature cryostat) } \\
: \quad \mathrm{B}=0 \mathrm{~T} \\
-\quad \mathrm{B}=0.1 \mathrm{~T} \| \mathrm{b} \\
-\mathrm{B}=0.02 \mathrm{~T} \| \mathrm{c}\end{array}$ & $\begin{array}{c}\text { L94-345 \& } \\
\text { L94-346 }\end{array}$ \\
\hline 3 & $I_{c}$ vs. $300 \mathrm{~K} \rightarrow 77 \mathrm{~K} \rightarrow 300 \mathrm{~K}$ for 50 thernal cycles & L94-345 \\
\hline 4 & $L_{c}$ vs. $0-1000$ A for 600 cycles & L94-346 \\
\hline 5 & End connection joint resistivities @ $77 \mathrm{~K}$ & L94-345 \\
\hline 6 & Irreversible strain limit @ $77 \mathrm{~K}$ & $\begin{array}{c}\text { L94-345 \& } \\
\text { L94-346 }\end{array}$ \\
\hline
\end{tabular}

${ }^{\mathrm{a}} \mathrm{I}_{\mathrm{c}}=$ critical current

Specific resistivities of metallic contacts to the superconductive cores of American Superconductor Corporation (ASC) tape samples comparable to those used in the composite bars were measured by the lap-joint method.6,7 Half-joint resistivities at $77 \mathrm{~K}$ ranged from 0.031 to $0.037 \mu \Omega \cdot \mathrm{cm}^{2}$. The values consisted of contributions from the silvergold/superconductor interface, one thickness of the silver-gold sheathing, and $1 / 2$ thickness of a minimal quantity of tin-lead solder used to form the lap joints tested.

Lap-joint resistivity tests were done also with the specially formed silver metal connectors sintered to the tapes in Sample L94-345. The average resistivity of the half-joints at $77 \mathrm{~K}$, including the contribution from the silver connector and its sintered interface to the tapes, was $\approx 1 \mu \Omega \cdot \mathrm{cm}^{2}$. 


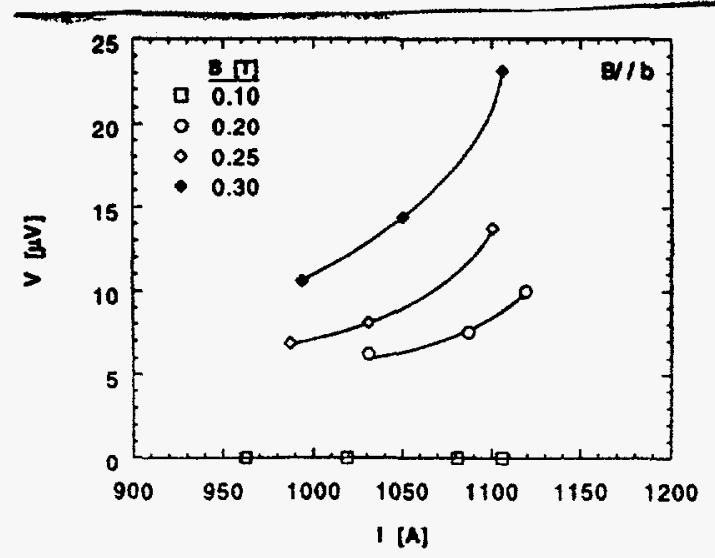

Fig. 4. Sample L94-345 voltage drop vs. current @60 K@B/h

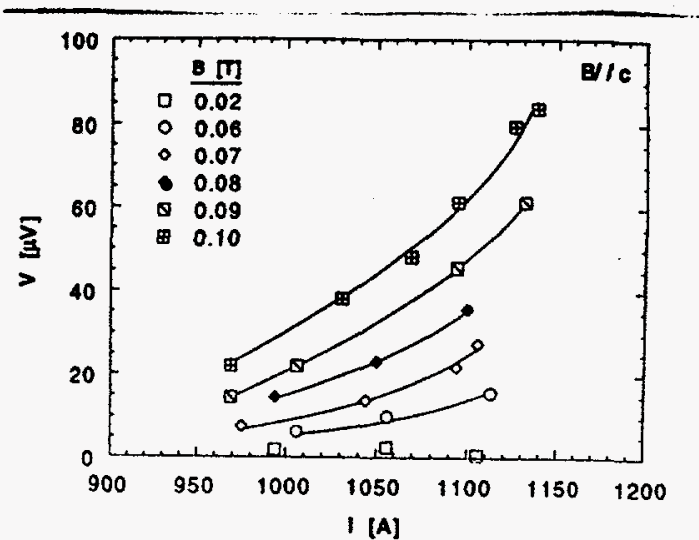

Fig. 5. Sample L94-345 voltage drop vs. current @ $60 \mathrm{~K} @ \mathrm{~B} / / \mathrm{c}$

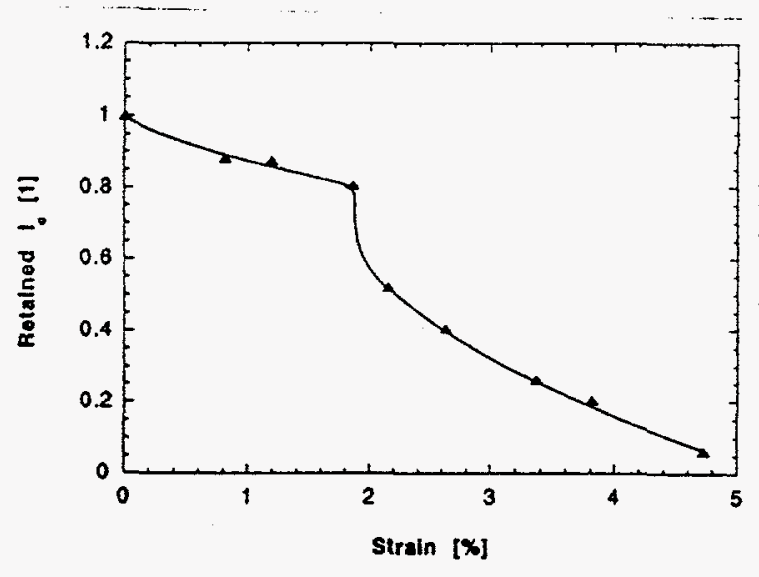

Fig. 6. Sample $L 94-346$ variation of retained $I_{C}$ with axial strain

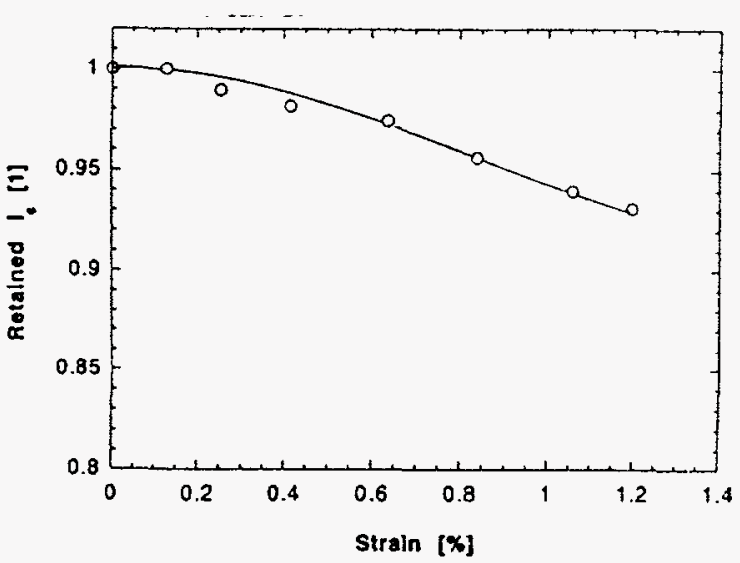

Fig. 7. Sample $194-345$ variation of retained $I_{C}$ with axial strain

Strain tolerance evaluation of the composite conductor elements was carried out by subjecting the conductor elements to room-temperature tensile strains and then testing for $I_{c}$. The specimen was loaded at $300 \mathrm{~K}$ to predetermined strains, unloaded, and then measured for $I_{C}$ in liquid nitrogen at $77 \mathrm{~K}$ and $0 \mathrm{~T}$. This process was repeated with increasing strains until sample failure. Sample L94-346 fractured completely at a strain of $\approx 5 \%$. Figure 6 shows the variation of retained $\mathrm{I}_{\mathbf{c}}(\%)$ with axial strain. Figure 7 shows a typical variation of retained $\mathrm{I}_{\mathrm{c}}(\%)$ with axial strain for Sample $\mathrm{L} 94-345$. Greater than $90 \% \mathrm{I}_{\mathrm{c}}$ was retained at $1.2 \%$ strain.

\section{PROTOTYPE CURRENT LEAD ASSEMBLY}

A prototype middle-stage assembly was designed and is being constructed. The prototype assembly is being employed to evaluate safety lead brazing, middle-stage machining, conductor element soldering, LTS cable fabrication, and quality control methods. 


\section{CURRENT LEAD ASSEMBLY PERFORMANCE EVALUATION}

The HTS lead assembly, consisting of the conventional gas-cooled upper stage and the HTS middle stage, will be tested in two phases. The first phase will consist of performance evaluations of the conventional upper stage beginning with initial evaluations of the background heat load of the test cryostat vessel without the upper stage present. Once the background heat load of the test cryostat has been established, the upper stage will be installed and heat load measurements will be performed at both zero current and operating current $(16,000 \mathrm{~A})$ plus an additional $10 \%$. Initial helium mass flow rates in the gas-cooled lead will be based on design calculations for the modified lead. A preliminary parametric study of the optimal mass flow and inlet temperature will be performed. These values will be used initially during the second phase of testing.

During the second phase of testing, the HTS portion of the current lead will be attached via a screw connection to the conventional upper stage. Initially, mass flow rates and inlet temperatures to the gas-cooled upper stage will be based on results obtained during the first phase of testing, with adjustments based on the additional calculated heat loads of the HTS portion of the current lead. Testing will begin by ramping the current lead assembly to operating current plus $10 \%(17,600 \mathrm{~A})$ in zero applied field. The next test will consist of applying an external magnetic field of $0.2 \mathrm{~T}$ perpendicular to the axis of the lead assembly and ramping the current lead to $17,600 \mathrm{~A}$. The external magnetic field will be supplied by a split solenoid magnet. Requirements for the external field are that it provide $0.2 \mathrm{~T}$ field with an active region of $10 \mathrm{~cm}$ in the axial direction, homogeneous to within $20 \%$, in a clear bore $>15 \mathrm{~cm}$. The active region of the field will be positioned at the warm end of the middle stage. A final parametric study to determine the optimal helium mass flow rate and inlet temperature will be performed at both zero current and operating current in an $0.2 \mathrm{~T}$ applied field. Once the optimal flow rate and inlet temperature have been established, heat load measurements will be performed at zero current and operating current in an $0.2 \mathrm{~T}$ field.

The next tests will be for reliability. The current lead assembly will undergo three separate sets of five thermal cycles and 70 electrical cycles, for a total of 15 thermal cycles and 210 electrical cycles. A thermal cycle is defined as room temperature $\rightarrow 100 \mathrm{~K} \rightarrow$ room temperature. An electrical cycle is defined as zero current $\rightarrow$ operating current $\rightarrow$ zero current at a ramp rate of $50 \mathrm{~A} / \mathrm{s}$ increasing and $200 \mathrm{~A} / \mathrm{s}$ decreasing.

The final tests of this phase will be the safety lead test, which will use two different methods. The first will be at operating current, magnetic field, and optimal inlet gas temperature. Mass flow will initially start at the optimal flow rate and slowly be decreased to a predetermined minimum value. The second method will be at operating current, magnetic field, and optimal flow rate. Inlet gas temperature will initially start at the optimal value and slowly increase toward the critical transition temperature $(B, I)$ of the HTS material.

\section{CONCLUSIONS}

- An HTS current lead with a 16-kA operating current has been designed for incorporation into a near-term, 0.5-MWh-capacity SMES system. The helium-gas-cooled upper-stage lead operates between 300 and $60 \mathrm{~K}$. Features include multiple gas flow passages and two-stage heat exchange. The $60-\mathrm{K}$ heat load for both leads is $196 \mathrm{~W}$. The conduction-cooled middle-stage lead operates between 60 and $5 \mathrm{~K}$. Current flow is shared by a cylindrical array of 18 parallel composite conductor elements fabricated from $\mathrm{Bi}-2223$ PIT tapes and having a silver-with-gold alloy sheath. Protection is provided by a stainless steel safety lead installed in parallel to the conductor element array. The $5-\mathrm{K}$ heat load for both leads is $11.2 \mathrm{~W}$.

- Two preproduction conductor elements have been evaluated relative to their performance specifications. Critical current @ $60 \mathrm{~K} @ \mathrm{~B} / / \mathrm{h}$ and $\mathrm{B} / \mathrm{c} @ 1 \mu \mathrm{V} / \mathrm{cm}$ was measured in a pulsed-current mode. One sample conductor element was subjected to 50 thermal cycles of $300 \mathrm{~K} \rightarrow 77 \mathrm{~K} \rightarrow 300 \mathrm{~K}$, with no significant change in $\mathrm{I}_{\mathrm{C}}$. One sample conductor element was subjected to 600 electrical ramp cycles corresponding to those predicted for the SMES current lead application, with no significant change in $\mathrm{I}_{c}$. Specific resistivities of metallic 
contacts to the superconductive cores of tape samples comparable to those used in the composite bars were measured. Half-joint resistivities at $77 \mathrm{~K}$ ranged from 0.031 to 0.37 $\mu \Omega-\mathrm{cm}^{2}$. Lap-joint resistivity tests were done with the specially formed silver metal connectors sintered to the tapes. The average resistivity of the half-joints at $77 \mathrm{~K}$, including the contribution from the silver connector and its sintered interface to the tapes, was about 1 $\mu \Omega-\mathrm{cm}^{2}$. Both sample conductor elements were evaluated for their irreversible strain limit. Greater than $90 \% \mathrm{I}_{\mathrm{c}}$ was retained at $1.2 \%$ strain. The sample conductor elements displayed a high degree of structural and electrical integrity, especially because they each were handled many times by various individuals but displayed no discernible performance degradation.

- A prototype middle stage assembly is being constructed for the purpose of evaluating manufacturing methods.

- Current lead assembly performance evaluation program will be carried out. Included will be performance of the upper stage, the integrated lead assembly, and safety and reliability studies.

\section{ACKNOWLEDGMENTS}

The authors gratefully acknowledge the technical contributions of Y. S. Cha, K. Duncan, D. J. Evans, E. Hudak, T. E. Kasprzyk, and J. Ulandy, as well as the manuscript preparation skills of J. A. Stephens and the editorial contributions of C. A. Malefyt. Work at ANL was supported by the U.S. Department of Energy, Energy Efficiency and Renewable Energy, as part of a program to develop electric power technology, under Contract W-31-109-Eng-38. Work at Babcock \& Wilcox was conducted as a part of the company's SMES development program.

\section{REFERENCES}

1. R.C. Niemann, Y.S. Cha, J.R. Hull, C.M. Rey, and K.D. Dixon, Design of a high-temperature superconductor current lead for electric utility SMES, IEEE Trans. on Appl. Superconductivity 5:789 (1995).

2. H. Fujishiro, M. Ikebe, K. Noto, M. Matsukawa, T. Sasaoka, K. Nomura, J. Sato, and S. Kuma, Low thermal conductive $\mathrm{Bi}-2223$ tapes sheathed with Ag-Au alloys, IEEE Trans. Magnetics 301:645 (1994).

3. T. Sasaoka, T. Umezawa, A. Nomoto, N. Tatsumi, and M. Seido, Power current leads using Ag-sheathed high- $\mathrm{T}_{\mathrm{c}}$ superconducting tapes, in Advances in Superconductivity IV, Proc. 4th Intl. Symp. on Superconductivity (ISS '91), H. Hayakawa and N. Koshizuka, eds., Springer-Verlag, New York (1992), pp. 621-624.

4. S.W. Van Sciver, Y.S. Hascicek, W.D. Markiewicz, L.R. Motowidlo, D.R. Hazelton, and P. Haldar, Strain dependence of $\mathrm{Bi}-2223$ tape conductors for application in high field magnets, in Advances in Superconductivity V, Proc. 5th Intl. Symp. on Superconductivity (ISS '92), Y. Bando, ed., SpringerVerlag, New York (1993), pp. 819-822.

5. K.H. Sandhage, G.N. Riley, and W.L. Carter, Journal of Metals 43:21 (1991).

6. H. Chi-Shiung, G.H. Haertling, and M.D. Sherrill, Rev. Sci. Instrum., :1317 (1991).

7. R. Birkhahn, N. Browning, A. Youngdahl, M. Lanagan, and R. Poeppel, Applied Superconductivity 2:67 (1994). 